\title{
Pachymeningitis and Cerebral Abscess Complicating Chronic Osteomyelitis
}

\section{Fah Bouaré ${ }^{*}$, Mehdi Laghmari ${ }^{1}$, Davis Mpando $^{1}$, Samuel Opoku Gyamfi $^{2}$, Mohamed Lmejjati ${ }^{1}$, Houssine Ghannane ${ }^{1}$ and Said Ait Benali $^{1}$}

${ }^{1}$ Department of Neurosurgery, Mohammed VI University Hospital, Cadi Ayyad University, Marrakech, Morocco

${ }^{2}$ Faculty of Medicine, Medical Research Thesis, Marrakech, Morocco

*Corresponding Author: Fah Bouaré, Department of Neurosurgery, Mohammed

VI University Hospital, Cadi Ayyad University, Marrakech, Morocco.
Received: February 28, 2020

Published: March 30, 2020

(C) All rights are reserved by Fah Bouaré., et al.

\begin{abstract}
Intracranial pachymeningitis (ICPM) is a chronic inflammatory thickening of the dura mater. They are relatively rare and may be secondary or idiopathic. We report an illustrative case with literature review. This is a 56-year-old diabetic insulin patient with a history of neglected head trauma with permanent subacute headaches and vertigo associated with fever and confusion. Upon examination, he had sequelae of right temporal sore with emission of pus, and monoparesis of the left upper limb. A cerebral CT scan made without and contrast material, found a right temporal bone defect, a right fronto-temporo-parietal bone thickening, a right frontal image in cockade and sub-factorial cerebral herniation. Surgical exploration found a cerebral abscess with thickening of bone and dura mater. Pathological examination concluded on chronic osteomyelitis and chronic inflammatory infiltration of the dura mater. The bacteriological examination found a flora made of negative coagulase Staphylococcus, Enterobacter cloacae, beta-hemolytic Streptococcus. This was treated with triple antibiotherapy (ceftriaxone, metronidazole, vancomycin) with a good evolution of brain abscess. The etiologies of pachymeningitis in literature are mainly inflammatory, carcinomas, tuberculosis and trauma. The treatment must be adapted on a case by case basis.
\end{abstract}

Keywords: Pachymeningitis; Cerebral Abscess; Chronic Osteitis; Head Trauma

\section{Background}

Intracranial pachymeningitis (ICPM) is a chronic inflammatory thickening of the dura mater. They are relatively rare and may be secondary or idiopathic [1]. We report an illustrative case with an enlightened literature review.

\section{Clinical Case Study}

$\mathrm{He}$ is a 56-year-old insulin-dependent diabetic man with a history of neglected head trauma with permanent subacute headaches and vertigo associated with fever and confusion. Upon examination, he had sequelae of a right temporal sore with emission of pus and monoparesis of left upper limb. A cerebral computed tomography (CT) scan with and without contrast injection (Figure 1-3) shows a right temporal bone defect, pneumocephalus, right fronto-temporo-parietal bone thickening, a right frontal image in cockage, with edema exerting a mass effect and resulting in cere- bral herniation. Surgical exploration (Figure 4) found a cerebral abscess by aspiration puncture, osteomyelitis of the cranial flap and chronic inflammatory infiltration of the dura mater. Pathological examination (Figure 5) found chronic osteomyelitis of the skull and chronic inflammatory infiltration of the dura mater. The bacteriological examination found a flora made of negative coagulase Staphylococcus, Enterobacter cloacae and beta hemolytic Streptococcus. The patient was placed on triple antibiotherapy composed of ceftriaxone $2 \mathrm{~g}$ x 2 per day for 4 weeks, metronidazole $500 \mathrm{mg} \mathrm{x}$ 2 per day for 4 weeks, vancomycin $1 \mathrm{~g} \times 2$ per day for 4 weeks. After a good clinical evolution, the patient was discharged on oral antibiotherapy consisting of cefixime $200 \mathrm{mg} \times 2$ per day, metronidazole $500 \mathrm{mg}$ x 2 per day, ciprofloxacin $500 \mathrm{mg}$ x 2 per day. The patient was seen 6 months later for emission of pus through the temporal scalp. A cerebral CT scan (Figure 6) showed a clear decrease in cerebral abscess and a persistence of the dural thickening. 


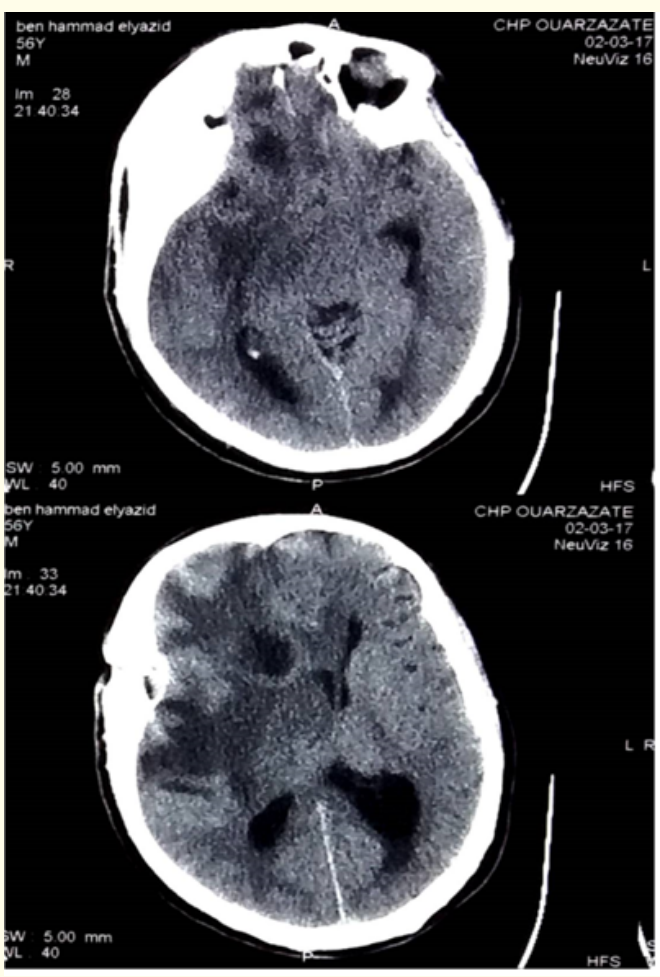

Figure 1: Head CT Scan without injection showing bone thickening with right frontal hypo dense image and edema.

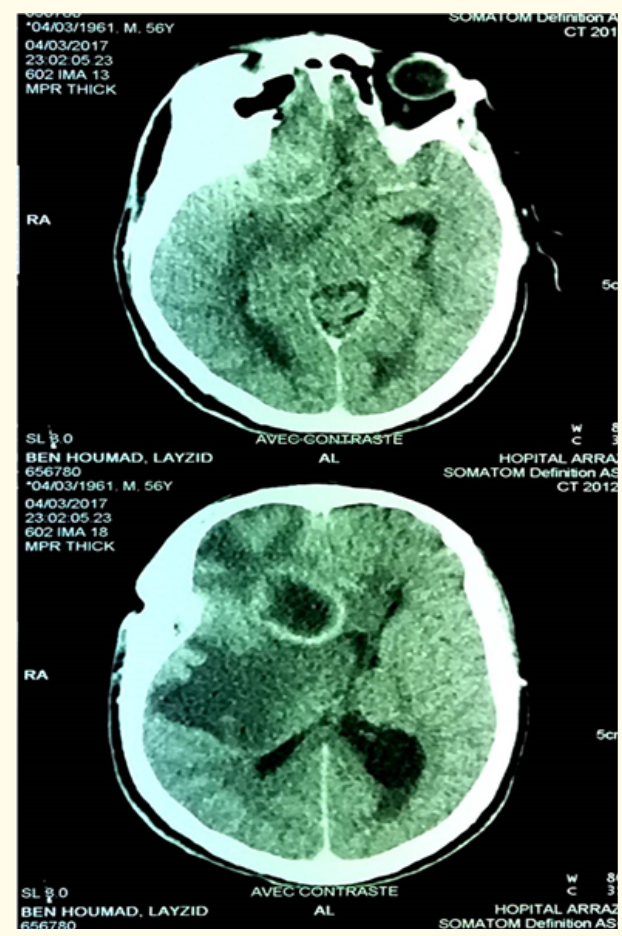

Figure 2: Head CT Scan with parenchymal injection showing a right frontal cockade image.

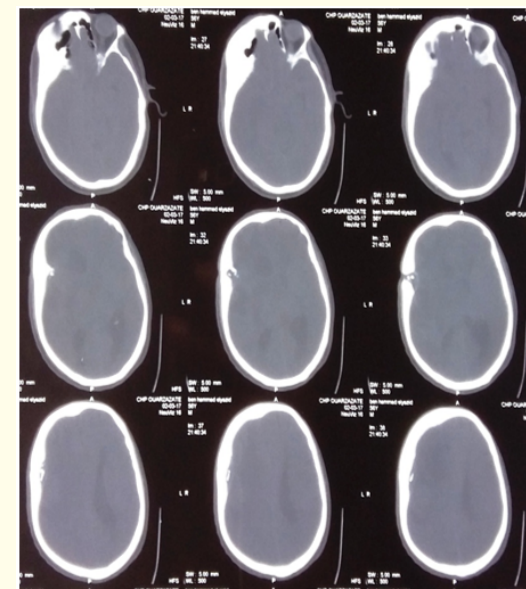

Figure 3: Bone head CT Scan showing a thickened temporo-parieto-frontal bone.

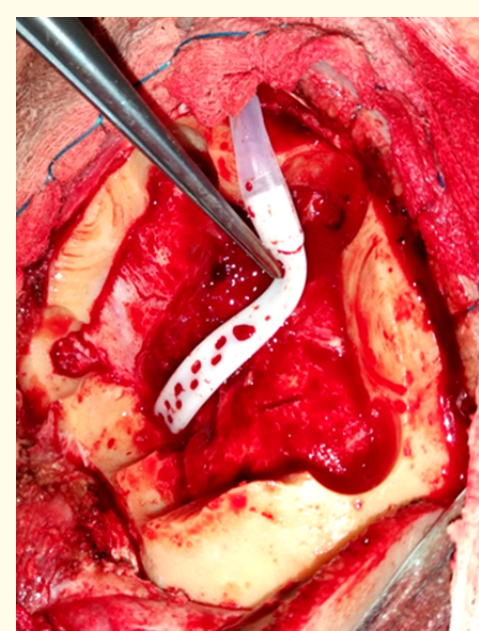

Figure 4: Surgical exploration, showing cranial thickening. A Jackson-Pratt drain was placed after the intervention.

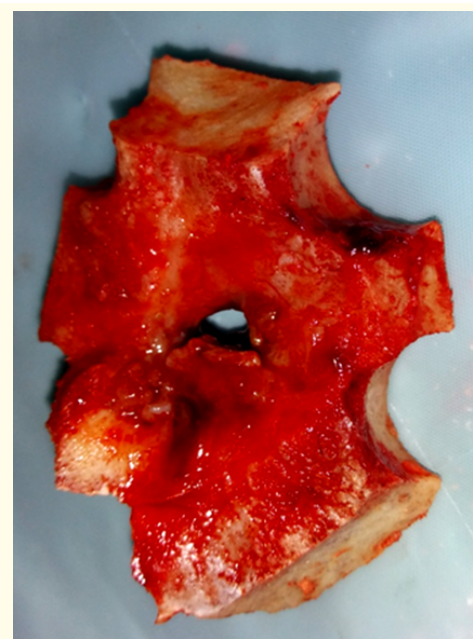

Figure 5: Per-operatory cranial flap with osteomyelitis. 


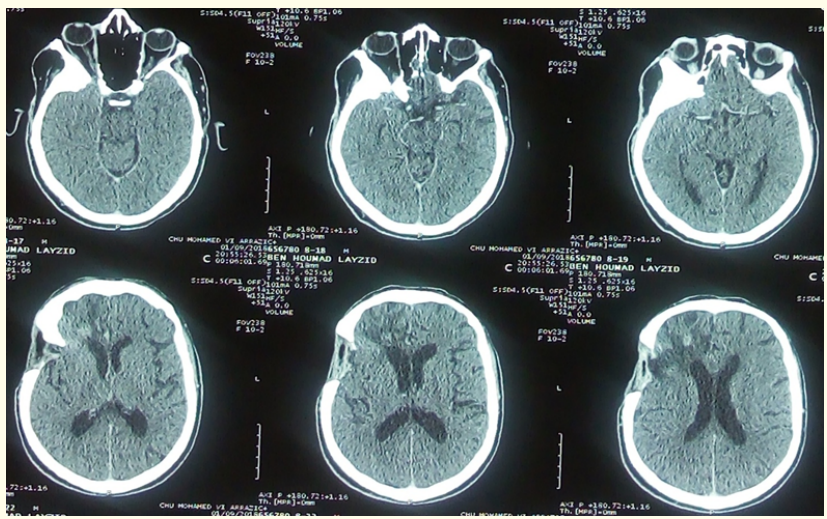

Figure 6: Cranial CT scan showing a good evolution of the brain abscess with a slight persistence of the thickening of the dura matter.

\section{Discussion}

It is an osteomyelitis secondary to a neglected open depressed fracture. Osteitis led to pachymeningitis and cerebral abscess.

The cranial dura mater is a thick and resistant envelope that covers the brain [2]. It is also called pachymeninge we can see on figure 7 [3]. Pachymeninge may be the site of chronic inflammation with inflammatory infiltration of lymphocytes with fibrosis leading to thickening of the dura mater [4]. It occurs with a peak frequency around the $6^{\text {th }}$ decade and predominates in men [1].

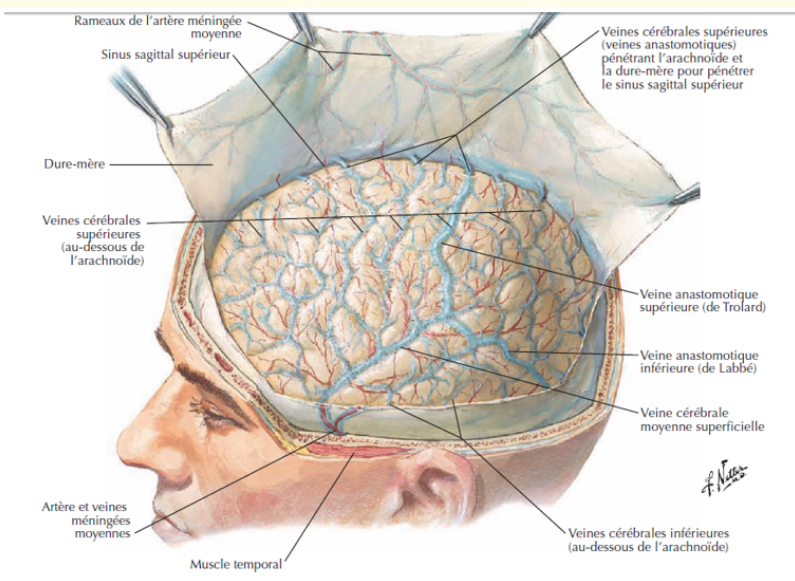

Figure 7: Anatomical view of the dura matter [3].

The clinical aspect of pachymeningitis is dominated by chronic headaches. Associated signs are according to the lesion topography. The cranial pairs (outside the I) can be damaged to varying degrees, especially VIII. Cavernous sinus involvement may lead to optic and oculo-motor neuropathy. The XI is often spared because of its somewhat caudal emergence at the level of the brainstem. A change in convexity can be responsible for epileptic seizures [5].
The imaging of intracranial pachymeningitis is based on CT scan and especially MRI which allows early diagnosis, assesses its importance and extension and detects a possible complication [1]. In our case, the cerebral CT scan was not contributive enough, the diagnosis was retained given the thickening of the dura mater per-operatively and its chronic inflammatory infiltration on pathological examination. Its association with a thickened bone, in chronic osteitis, gives argument for a differential diagnosis because it could evoke an en plaque meningioma.

The pathological study of ICPM shows a chronic inflammation of the dura mater with infiltration by lymphocytes [4]. In its etiologies, the first cases of pachymeningitis were related to tuberculosis and syphilis [6]. Others etiologies are noted: sarcoidosis, Horton's disease, Behcet's disease, chronic intracranial hypotension, leptomeningeal carcinomas [1] or idiopathic pachymeningitis [7].

The treatment is adapted on a case by case basis. Immunosuppressive therapy is generally effective in systemic or idiopathic immune dysfunction, although parenchymal involvement has not yet been found [4]. Anti-bacillary drugs are prescribed in the case of tuberculosis [1]. In our case, pachymeningitis was associated with chronic osteomyelitis and a cerebral abscess with a good clinical and radiological evolution under antibiotherapy, corroborating the infectious etiology of common germs.

\section{Conclusion}

It is a chronic inflammation of the dura mater with secondary or idiopathic etiologies. The real danger must be that of a carcinomatous origin. The diagnosis must be evoked on the MRI. Its association with chronic osteomyelitis with thickened bone should also be suggestive of en plaque meningioma. The treatment must be adapted on the suspected etiology.

\section{Conflicts of Interests}

The authors declare no conflict of interest.

\section{Authors' Contribution}

Each author contributed to the writing of this manuscript, either by the correction, the reading, or the translation into English.

\section{Acknowledgment}

Thanks to all co-authors of this manuscript.

\section{Bibliography}

1. N Ech-Cherif., et al. "Les pachyméningites intracrâniennes: aspects TDM et IRM”. Feuillets de Radiologie 52.5 (2012): 298.

2. Richard L Drake., et al. "Gray's anatomie pour les étudiants". Elsevier Masson (2006): 818.

3. Frank H Netter. "Atlas d'anatomie humaine". $5^{\text {th }}$ édition. Elsevier Saunders, USA: 101. 
4. Olivier Fain and A Mekinian. "Les pachyméningites". La Revue De Médecine Interne, Elsevier (2017).

5. Brüggemann N., et al. "Cranial pachymeningitis: a rare neurological syndrome with heterogeneous aetiology". Journal of Neurology, Neurosurgery, and Psychiatry 81.3 (2010): 294298.

6. Charcot JM and Joffroy A. "Deux cas d'atrophie musculaire progressive avec lésions de la substance grise et des faisceaux antérolatéraux de la moelle épinière". Archives of Physiology and Normal Pathology 2 (1869): 354-367, 629-649, 744-769.

7. Naffziger HC and Stern WE. "Chronic pachymeningitis: report of a case and review of the literature". Archives of Neurology and Psychiatry 62.4 (1949): 383-411.

\section{Assets from publication with us}

- Prompt Acknowledgement after receiving the article

- Thorough Double blinded peer review

- Rapid Publication

- Issue of Publication Certificate

- High visibility of your Published work

Website: www.actascientific.com/

Submit Article: www.actascientific.com/submission.php Email us: editor@actascientific.com

Contact us: +919182824667 